\title{
Desenvolvimento de um Sistema de Informação para Acidentes de Trânsito Ocorridos em Pernambuco
}

\author{
Development of an Information System for Traffic Accidents in Pernambuco \\ Mateus Alves Martins ${ }^{* 1}$, Thalles Vitelli Garcez ${ }^{2}$ \\ ${ }^{1}$ PPGEPCAA - Programa de Pós-graduação em Engenharia de Produção do Centro Acadêmico do Agreste, \\ Universidade Federal de Pernambuco, Pernambuco, Brasil. \\ ${ }^{2}$ CDSID - Centro de Desenvolvimento em Sistemas de Informação e Decisão, Universidade Federal de \\ Pernambuco, Pernambuco, Brasil.
}

\section{N FO A R T I GO}

\section{Palavras-chave:}

Acidentes de trânsito,

Rodovias federais,

Pernambuco,

Sistema de Informação.

$\overline{\text { ARTICLE INFO }}$

Keywords:

Traffic accidents,

Federal roads,

Pernambuco,

Information System.

\begin{abstract}
RES U M O
Dado o elevado número de registros de ocorrências e pessoas envolvidas em acidentes de trânsito em rodovias federais, adicionado às diversas variáveis (fatores) presentes em cada ocorrência, registrados pela PRF em bancos de dados (BD); este trabalho propõe o uso de um Sistema de Informação (SI) que visa transformar os dados contidos no BD da PRF em informação, permitindo, desta forma, o acesso facilitado e "amigável" aos subsídios da acidentalidade de trânsito ocorrido nas rodovias federais do estado Pernambuco. A partir do SI proposto é possível acessar informações sobre: o perfil condutor, do trecho, do veículo, das relações sobre as variáveis e das correspondências entre elas. Portanto, o SI proposto se mostra útil por além de transformar dados em informações e facilitar o acesso a essas informações, ele possibilita que a partir das informações disponibilizadas, o usuário pode transformá-las em conhecimento de forma a auxiliar a tomada de futuras decisões.
\end{abstract}

\begin{tabular}{l}
\hline A B S T R A C T \\
Given the high number of records of incidents and people involved in traffic \\
accidents on federal roads, added to the various variables (factors) present in \\
each occurrence, recorded by the PRF in databases (BD); this paper proposes \\
the use of an Information System (IS) that aims to transform the data \\
contained in the PRF database into information, thus allowing easy and \\
"friendly" access to traffic accident subsidies on Pernambuco's federal roads. \\
From the proposed IS, it is possible to access information about: the driver \\
profile, the section road, the vehicle involved, the relationships about the \\
variables and the correspondences between them. Therefore, the proposed IS \\
proves to be useful in addition to transforming data into information and \\
facilitating access to this information, it enables that from the information \\
available, the user can transform it into knowledge in order to assist in making \\
future decisions.
\end{tabular}

\section{Introdução}

Acidentes de trânsito resultam em um elevado número de mortos, feridos e custos significativos de saúde e socioeconômicos, constituindo assim um importante problema de saúde pública e desenvolvimento no mundo

\footnotetext{
${ }^{*}$ Correspondência para autor:

mateus_alves_martins@hotmail.com (Martins, M. A.), tvgarcez@cdsid.org.br (Garcez, T. V.).
} 
(MORAIS NETO et al., 2013). Aproximadamente 1,35 milhões de pessoas morrem por ano vítimas de acidentes de trânsito, sendo que $93 \%$ das mortes ocorrem em países de renda baixa ou média. Além disso, entre 20 a 50 milhões de pessoas sofrem ferimentos não fatais, ocasionando para maioria dos países um custo de $3 \%$ do produto interno bruto. Em 2016, mortes por ferimento na estrada estava na oitava principal causa de mortes com 1,4 milhões de mortes (2,5\% do total de mortes) (WHO, 2018).

Em 2015, no Brasil foram registradas 38.651 fatalidades, fato que colocou o país na $3^{\text {a }}$ posição dos países com mais mortes no trânsito em termos de valor absoluto, atrás da Índia e China. Quando considerado a razão do número de mortes pelo número total de habitantes, o Brasil fica na $14^{a}$ posição, em média há 19,7 mortes por 100.000 habitantes (WHO, 2018).

Olhando para o panorama do estado de Pernambuco, ocorreram cerca de 3.600 mortes de um total aproximado de 57 mil acidentes entre os anos de 2007 a agosto de 2015, resultando em uma média de 6.712 acidentes por ano (MARTINS; GARCEZ, 2017).

Os registros de acidentes de trânsito das rodovias federais do Brasil estão armazenados nos bancos de dados disponibilizados pela Policia Rodoviária Federal (PRF), que são de livre acesso e estão separados por ano (de 2007 até 2019). Neste banco de dados contém fatos sobre as ocorrências e as pessoas envolvidas nos acidentes, tais como: causa e tipo do acidente, idade e sexo do envolvido, dentre outras variáveis. Visto a grande quantidade de ocorrências e pessoas envolvidas em acidente, tem-se como resultado que o banco de dados contém milhões de linhas onde cada linha representa um registro sobre determinada ocorrência de acidente ou uma pessoa envolvida. Porém, é importante destacar que além do grande volume de registros, eles estão em forma de dados, ou seja, são vistos como fatos crus, e para que passem a ter um significado é necessário transformá-los em informação através da organização e refinação dos mesmos, passando a ter valor adicional além dos fatos individuais. Os dados transformados em informação facilitam a tomada de decisão presente ou futura (ALMEIDA; RAMOS, 2002; STAIR; REYNOLDS; SILVA, 2011).

Com o objetivo de transformar a grande quantidade de dados dos acidentes de trânsito em informação e disponibilizá-los de forma prática, surge a necessidade do Sistema de Informação (SI), o qual tem como característica fornecer acesso rápido à informação, lidar com grandes volumes de dados de fontes diferentes, fornecer flexibilidade na apresentação e oferecer orientação textual e gráfica (ALMEIDA; RAMOS, 2002; STAIR; REYNOLDS; SILVA, 2011).

Dado a importância de estudos sobre acidentes de trânsito, o qual é considerado um problema mundial devido ao expressivo número de ocorrências adicionado a consequências imensuráveis, como a perda da vida humana, acrescentado à falta de um SI que trabalhe de forma a transformar o grande volume de dados registrados em informações acessíveis, este trabalho é justificado. O presente estudo busca auxiliar os interessados (população, governo e empresas) através do desenvolvimento de um SI cujo objetivo é transformar o imenso banco de dados em informação, assim como facilitar o acesso à informação e proporcionar a geração de conhecimento sobre o tema de forma efetiva, auxiliando na tomada de decisão de ações que venham a diminuir o risco de acidentes, ajudando assim no planejamento de programas de prevenção adequados à realidade da rodovia. A princípio considera-se que o usuário pode ser desde um condutor comum que busca informações sobre determinada rodovia, por exemplo, até o próprio governo que pode buscar informações sobre o panorama da acidentalidade para assim tomar decisões com base nessas informações.

Portanto, este trabalho tem como principal objetivo desenvolver um SI o qual permite a transformação de um o grande volume de dados referentes a acidentes de trânsito disponibilizados pela PRF em informação, possibilitando assim que conhecimento seja gerado a partir da disponibilização de informações. Para tanto, outros objetivos específicos são almejados, tais como: filtrar e tratar os dados referentes a acidentes de trânsito no estado de Pernambuco do ano de 2007 a 2016 a partir do banco de dados da PRF; utilizar da estatística descritiva e de correspondência para gerar entradas a serem armazenadas no SI e que servirão de saída do sistema; selecionar quais são as informações relevantes a serem evidenciadas pelo SI; e, desenvolver o SI dentro do Microsoft Excel a partir de Macro e funções lógicas, utilizando os acidentes de trânsito ocorridos em Pernambuco para exemplificação do SI.

\section{Referencial Teórico}

Um SI é constituído essencialmente por um banco de dados e uma base de modelos que possuem a interface de usuário, permitindo que os usuários manipulem e acessem facilmente o sistema, obtendo assim as informações desejadas (STAIR; REYNOLDS; SILVA, 2011). 
Os dados são fatos crus sobre um objeto. Já informação são dados que foram organizados, refinados e se apresentam de uma forma tal que podem ser usados para facilitar o processo de tomada de decisão presente ou futura, passando a ter significado, possuindo assim valor adicional além do valor dos fatos individuais. Para tanto, a transformação dos dados em informação é realizada por um processo, o qual consiste em um conjunto de tarefas realizadas para alcançar o resultado definido (ALMEIDA; RAMOS, 2002; STAIR; REYNOLDS; SILVA, 2011).

Já o SI é um conglomerado de elementos que interagem para alcançar objetivos, os elementos e os relacionamentos entre eles determinam o funcionamento do sistema, o qual possuem entradas, mecanismos de processamento, saídas e realimentação (STAIR; REYNOLDS; SILVA, 2011). Para isso, a comunicação do SI com o usuário se dar por meio de um diálogo, que pode ser através de relatórios programados, indivíduo intermediário, analista de apoio, perguntas e respostas, menu, linguagens de comando, entrada/saída e combinação (ALMEIDA; RAMOS, 2002).

É possível entender que SI nada mais é que um sistema focado no processamento de dados ou informações, mais precisamente, é um conjunto de elementos inter-relacionados que coleta (entrada), manipula (processo), armazena e disseminam dados e informações (saída). Portanto, sendo caracterizado por fornecer acesso rápido a informação, lidar com grandes volumes de dados de fontes diferentes, e fornecer relatório e flexibilidade na apresentação e oferecer orientação textual e gráfica, apoiando a análise em detalhes (STAIR; REYNOLDS; SILVA, 2011).

É importante destacar que para as informações serem realmente úteis, é necessário conhecimento, que "é a consciência e a compreensão de um conjunto de informações e os modos como essas informações podem ser úteis para apoiar uma tarefa específica ou para chegar a uma decisão" (STAIR; REYNOLDS; SILVA, 2011). Portanto, salienta-se que apenas as pessoas através de sua interpretação possuem a capacidade de gerar conhecimento.

\section{Trabalhos Relacionados}

A partir da verificação dos artigos percebe-se um potencial para a utilização de sistemas de informação para auxiliar e tratar o problema da acidentalidade em rodovias. Potencial esse não muito explorado quando verificado o cenário nacional.

\subsection{Acidentalidade em Pernambuco}

No que se referem à literatura dos últimos dez anos com foco acidentes de trânsito ocorridos no estado de Pernambuco, tem-se os trabalhos de Silva et al. (2011), Lima e Garcez (2015), Lima e Garcez (2016), Martins e Garcez (2017) e Martins e Garcez (2018).

No estudo de Silva et al. (2011) foi realizado um estudo espacial da mortalidade por acidentes de motocicleta em Pernambuco; já o trabalho de Lima e Garcez (2015) analisou a acidentalidade na BR-232/PE nos anos de 2007 a 2012 através de testes de hipótese; a pesquisa de Lima e Garcez (2016) fez uso da análise de correspondência simples e multivariada para explorar os acidentes ocorridos em Pernambuco do ano de 2007 a 2012; Martins e Garcez (2017) realizou uma análise descritiva dos acidentes em Pernambuco do ano de 2007 a agosto de 2015, criando também um mapa viário para visualização dos trechos críticos de acordo com a quantidade de acidentes; e por fim, no artigo de Martins e Garcez (2018) foi realizada uma pesquisa exploratória sobre os acidentes de trânsito em Pernambuco ocorridos de 2007 a 2016, através da análise de correspondência e de cluster.

\subsection{Sistema de Informação em acidentalidade de trânsito}

No que se refere a SI aplicados a acidentes de trânsito, tem-se como exemplo o trabalho de Török, Pauer e Berta (2017), no qual foi analisado o impacto de um SI Rodoviário na segurança no trânsito, destacando que a disponibilização de informações sobre os trechos críticos permite o aumento da segurança nas rodovias. De acordo com os resultados fornecidos, as categorias de "colisão entre veículos em movimento na direção de cruzamento" e "omissão de dar o direito de passagem" podem ser influenciadas pelo SI.

Korchagin et al. (2017) propõem em seu trabalho um sistema de informação o qual denominam por ROAD (Road Accident Consequences Elimination subsystem) que visa diminuir o número de acidentes e lesões associadas ao transporte rodoviário; minimizar os danos infligidos por acidentes rodoviários; diminuir o risco de qualquer tipo de ocorrência; melhorar a eficiência e segurança ecológica da manutenção do transporte rodoviário, o mesmo inclui: informação, subsistemas de monitoramento e recursos, baseando-se em um subsistema de informação altamente eficiente que fornece a interação entre os subsistemas de monitoramento e recursos unificados por entidades comuns de gerenciamento. 
Ryder et al. (2017), em seu estudo sobre prevenção de acidentes, utiliza um Sistema de Apoio a Decisão (SAD) que fornece avisos aos motoristas sobre os pontos frequentes de acidentes baseados em análises de localização aplicadas a um conjunto de dados de acidentes históricos nacionais, o sistema foi testado com 57 motoristas da Suécia, sendo mostrado que esses avisos resultam em uma melhoria significativa no comportamento do motorista ao longo do tempo, onde a eficácia do sistema está depende da personalidade do motorista.

\section{Desenvolvimento do Sistema de Informação}

Para a construção do SI foi utilizado à linguagem de programação Visual Basic for Applications (VBA) de modo a criar macros no Microsoft Excel, e funções lógicas, permitindo assim que as informações sejam mostradas de acordo com o que for requisitado pelo usuário. O Microsoft Excel (formato de planilha) foi escolhido porque o mesmo é conhecido pela população de forma geral até entidades do setor público e privado, facilitando assim a utilização do usuário já que a interface e os comandos já são familiares. Além disso, o banco de dados da PRF também está disponibilizado em planilhas, facilitando a criação e compatibilidade do banco do SI com o da PRF. Vale ressaltar que o SI apresentado é um protótipo, ou seja, suas funcionalidades encontram-se limitadas, sendo necessária a alimentação sistema com as informações a serem mostradas, não tendo assim um acesso direto ao banco de dados da PRF.

A Figura 1 representa o esquema para criação do SI, na qual é formado pelo BD construído pelo resultado da estatística descritiva e exploratória, por funções lógicas e macros pré-estabelecidas que se comunicam com a interface do usuário e o banco do SI, sendo responsável pela disponibilização da informação requisitada, e por fim, a interface usuário, onde o usuário colocará as entradas, interagir com o sistema e visualizar a saída.

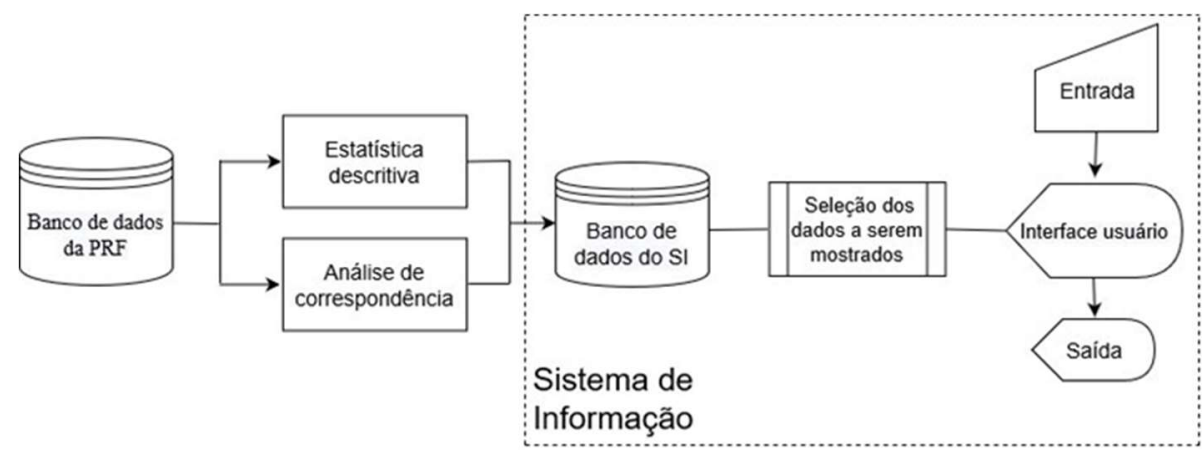

Figura 1 - Modelagem para o Sistema de Informação.

Fonte: os autores (2019).

Primeiramente, antes mesmo do SI propriamente dito, para a realização deste trabalho foi utilizado os bancos de dados sobre acidentes rodoviários disponibilizados pela PRF, e com base neles foram realizadas a priori uma abordagem descritiva e exploratória através da estatística descritiva e da análise de correspondência; ferramentas essas que geraram as informações que são utilizadas como saída do SI.

A estatística descritiva foi empregada, pois é necessária para a fase inicial do processo de estudo de dados, com o objetivo de organizar, resumir e descrever aspectos de um conjunto de características observadas ou compará-las (DOANE; SEWARD, 2014), facilitando assim a visualização dos dados. Como etapa posterior temse o uso da análise de correspondência, que segundo Greenacre 2007, consiste em uma técnica estatística útil para a análise de dados categóricos na forma de frequência numérica permitindo uma interpretação e compreensão mais rápida dos dados. Tal método tem como objetivo determinar a associação entre as linhas e colunas de uma tabela de contingência, expondo como as variáveis estão relacionadas.

De posse dos resultados gerados pela a análise descritiva e da análise de correspondência, deu-se início ao desenvolvimento do SI o qual mostrará os resultados obtidos das duas abordagens de acordo com o que for requisitado pelo usuário.

A partir da análise descritiva é possível verificar o panorama dos perfis requisitados. Mais especificamente, é mostrado informações sobre as causas, tipos de acidentes e estado físico dos envolvidos de acordo com o especificado. Os resultados são divididos por trecho, perfil do condutor, cruzamento do trecho com perfil do condutor, com o veículo e por fim o cruzamento dos três. Já pela análise de correspondência é mostrado as possíveis associações do perfil do condutor e veículo com as causas, tipos de acidentes e estados físicos. 


\subsection{Modelagem para o Sistema de Informação}

Uma vez pré-processado o BD da PRF para validação do banco de dados para inclusão ao BD do SI, tem-se o processamento das estatísticas descritivas e da análise exploratória (através da análise de correspondência). Portanto, conforme mostrado na Figura 1, o SI é formado por um banco de dados, o qual contém informações geradas pela estatística descritiva e exploratória.

No momento que o usuário informa os dados de entrada na interface da página inicial, as funções lógicas previamente criadas no sistema solicitam do BD do SI os resultados da estatística descritivas e exploratórias e as disponibilizam em células previamente selecionadas em abas de acordo com os perfis, dando origem a valores absolutos, porcentagens e gráficos. Estas abas são as opções de páginas as quais o usuário pode ter acesso através de um menu e botões atribuídos a macros, sendo as informações disponibilizadas são as saídas do sistema.

O esquema do Sistema de Informação proposto é mostrado na Figura 2. Os resultados gerados têm como base o perfil informado pelo usuário. Para isso, o usuário primeiramente irá se deparar com um display no qual ele selecionará o sexo e idade do condutor, o veículo, a BR e o trecho o qual objeto de estudo. As opções de escolha são disponibilizadas através de listas previamente elaboradas em determinadas células do Excel. O uso dessas listas evita erros de entrada e o conteúdo previamente conhecido das mesmas facilitam com que as funções lógicas mostrem peguem e disponibilizem a informação requisitada.

Após finalizar a entrada através do click no botão atribuído a macro que direciona para o menu o qual contém botões que direcionam aos displays os quais o usuário pode visualizar as saídas, além de poder voltar para mudar os dados de entrada. As informações são disponibilizadas nos displays simultaneamente ao momento que o usuário seleciona a entrada.

Os displays os quais o usuário percorre e a atividade que ele deve fazer são mostradas na Figura 2, sendo que "Página inicial" e "Menu" são displays os quais o usuário deverá interagir, as outras seis interfaces são as saídas do SI que o usuário pode escolher ver.

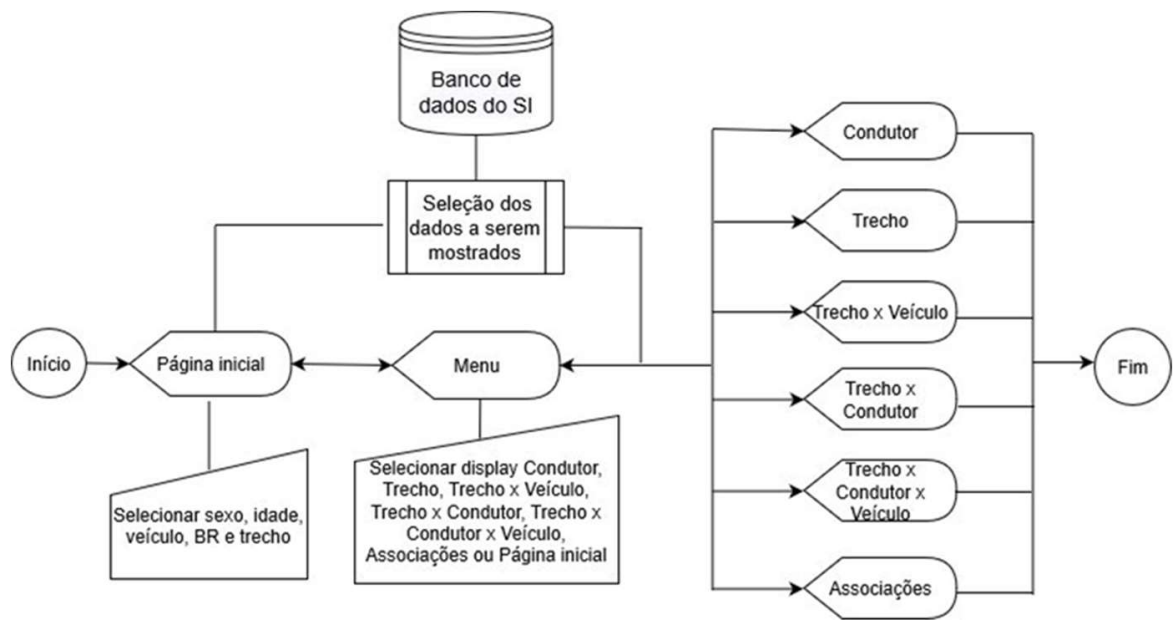

Figura 2 - Esquema do Sistema de Informação.

Fonte: os autores (2019).

\subsection{Principais saídas do SI proposto}

Como uma proposta inicial, o SI mostra os resultados de acordo com o perfil do condutor (sexo e idade), o veículo e o trecho escolhido. Como pode ser visto na Figura 3, na página inicial do sistema encontram-se espaços os quais serão preenchidos pelo usuário de acordo com seu perfil e necessidades. Todas as opções possíveis já estão listadas, bastando, assim, apenas o usuário selecionar uma delas, como demonstrado na Figura 4. Ainda na página inicial estão os botões de "Limpar" o qual serve para apagar as lacunas preenchidas e o botão de "Executar" o qual tem como função executar o algoritmo e enviar o usuário para o menu. 


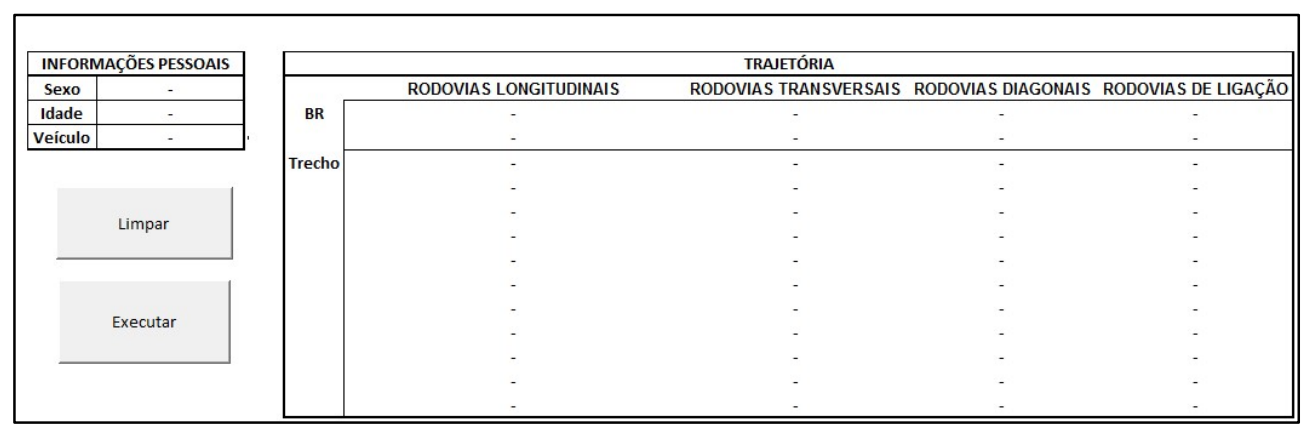

Figura 3 - Página inicial.

Fonte: os autores (2017).

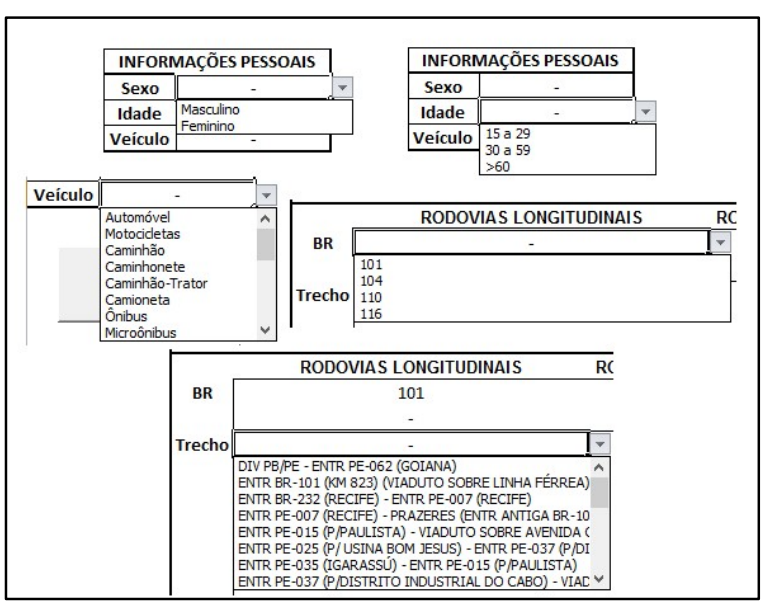

Figura 4 - Opções de entrada.

Fonte: os autores (2017).

A Figura 5 representa o menu no qual o usuário pode escolher qual resultado ele quer ver. O decisor pode escolher entre sete opções, que são: i) ver quais são as associações do seu perfil de condutor e veículo, tanto de forma geral quanto específico para o trecho (Associações); ii) ir para as informações referidas somente ao trecho (Trecho); iii) ser direcionado para as informações referentes ao seu perfil de condutor de acordo com o trecho (Trecho x Condutor); iv) ver outputs gerados para o seu perfil de condutor, independente do trecho escolhido (Condutor); v) ir para as informações que relacionam o trecho e o veículo escolhido (Trecho x Veículo); vi) ser direcionado para a aba que contém as informações específicas para seu perfil e veículo escolhido dentro do trecho determinado (Trecho x Condutor x Veículo); e por último, vii) tem-se o botão que direciona para a tela inicial (Página inicial).

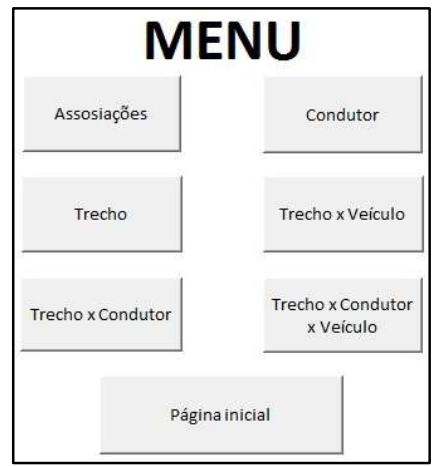

Figura 5 - Menu.

Fonte: os autores (2017). 
Para exemplificar uma situação prática do uso do SI, foi considerado que foi requisitado por um usuário informações sobre condutores do sexo masculino, com idade entre 15 a 29 anos, o tipo de veículo selecionado é um automóvel; que utilizará o trecho "ENTRE PE-035 (IGARASSÚ) - ENTRE PE-015 (P/PAULISTA)" da BR 101/PE.

O SI mostra diversos resultados ao usuário, tais como: visão geral descritiva das estatísticas relacionada ao perfil do condutor, tipo de veículo e trecho da BR (Figura 6 a Figura 10).

A Figura mostra o conteúdo da aba "Trecho", nela é possível ver as informações referentes ao número de pessoas envolvidas em acidentes no trecho e a participação que representa para Pernambuco, os tipos de acidentes, suas frequências e respectivas participações, a quantidade de condutores envolvidos e o que isso representa quando levado em consideração o total de envolvidos, a quantidade de ocorrências naquele trecho e a participação que esse valor representa para o estado de Pernambuco, as causas juntamente com suas frequências e participações, e por fim tem-se três gráficos em forma de pizza, que são: o do estado físico dos envolvidos, o estado físico dos condutores e a classificação dos acidentes.

Como análise dessas informações, no exemplo aplicado, o usuário facilmente pode perceber no trecho em estudo que: cerca de 7\% das pessoas envolvidas em acidentes no estado de Pernambuco foi nesse trecho, sendo que cerca de $80 \%$ das pessoas ficaram ilesas; da mesma forma, este trecho envolveu cerca de $7 \%$ de todas ocorrências já ocorridas nas rodovias federais de Pernambuco, com cerca de $70 \%$ dos acidentes sem vítimas; tendo como tipos principais de acidentes a colisão lateral $(38,09 \%)$, colisão traseira $(33,44 \%)$ e colisão transversal $(12,82 \%)$; além disso, cerca de $84 \%$ dos condutores envolvidos ficaram ilesos após o acidente; e a principal causa foi falta de atenção com aproximadamente $58 \%$.

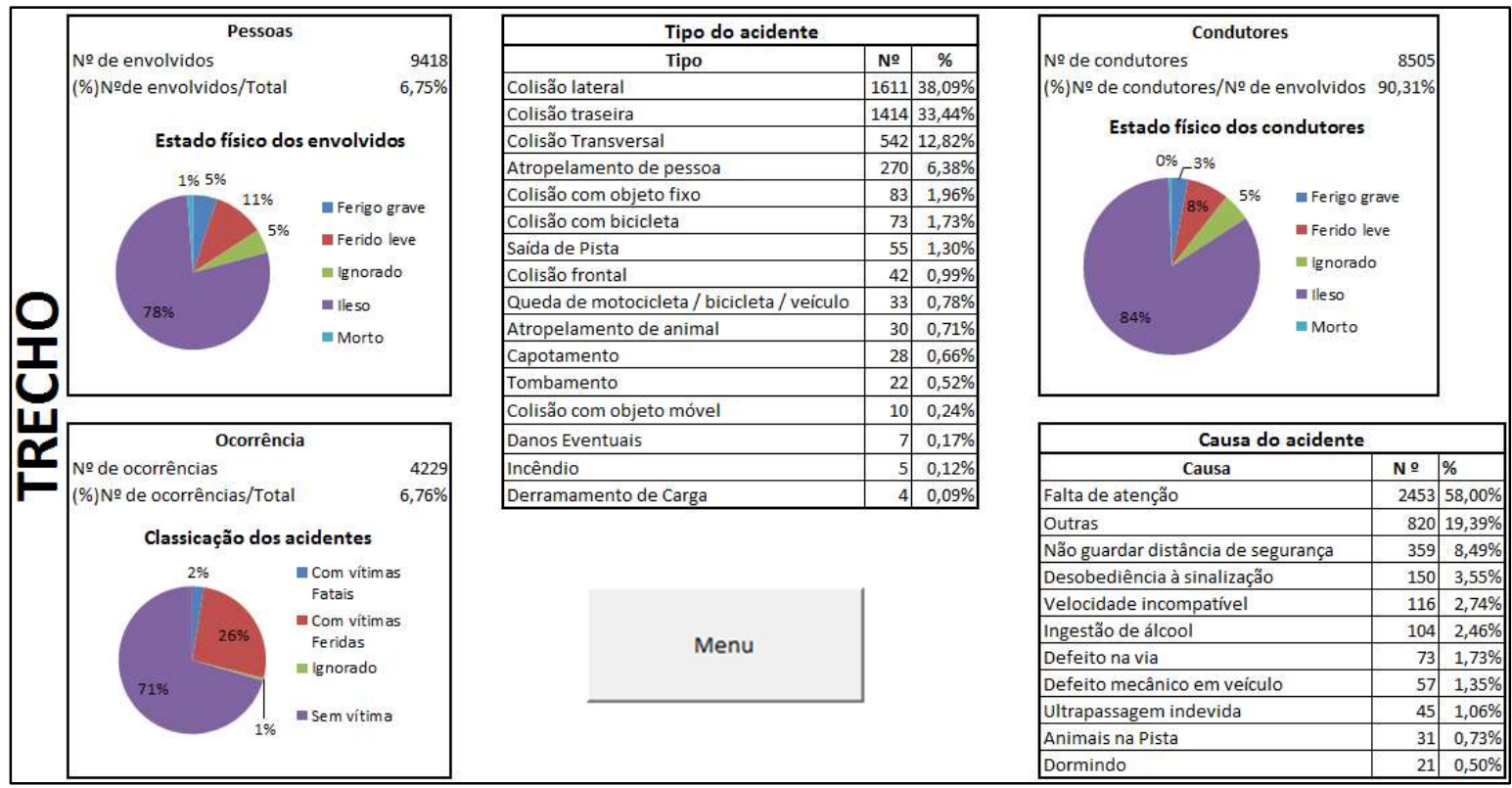

Figura 6 - Dados descritivos por trecho.

Fonte: os autores (2017).

Na Figura 7 é possível observar a tela do "Perfil do Condutor", nela tem-se como outputs o número de condutores de todo o estado de Pernambuco com o perfil indicado e a distribuição do estado físico dos mesmos através do gráfico em forma de pizza, há também duas tabelas, a primeira contém todas as causas, as frequências das causas e sua respectiva participação de acordo com o perfil do condutor determinado no início, de modo parecido encontram-se os tipos de acidentes, com suas quantidades de aparições e respectiva participação em forma de porcentagem.

Já a Figura 8 representa a aba referente ao cruzamento do "Trecho x Condutor", nela é relacionado o perfil do condutor ( Figura 7, demonstrando assim de forma quantitativa o número de condutores com aquele perfil específico, envolvidos em acidentes no trecho selecionado, além disso, é mostrado também o gráfico da parcela que cada estado físico possui para o grupo dos condutores com aquele perfil e por fim, são mostradas as duas tabelas, uma 
com informações quantitativas sobre as causas dos acidentes e a outra sobre os tipos de acidentes, porém, estão agora restringidos apenas para aquele trecho e perfil do condutor em específico, acrescenta-se também como informação disponibilizada na página, a participação que o perfil do condutor escolhido possui em relação ao número total de condutores envolvidos, restrito ao trecho escolhido.

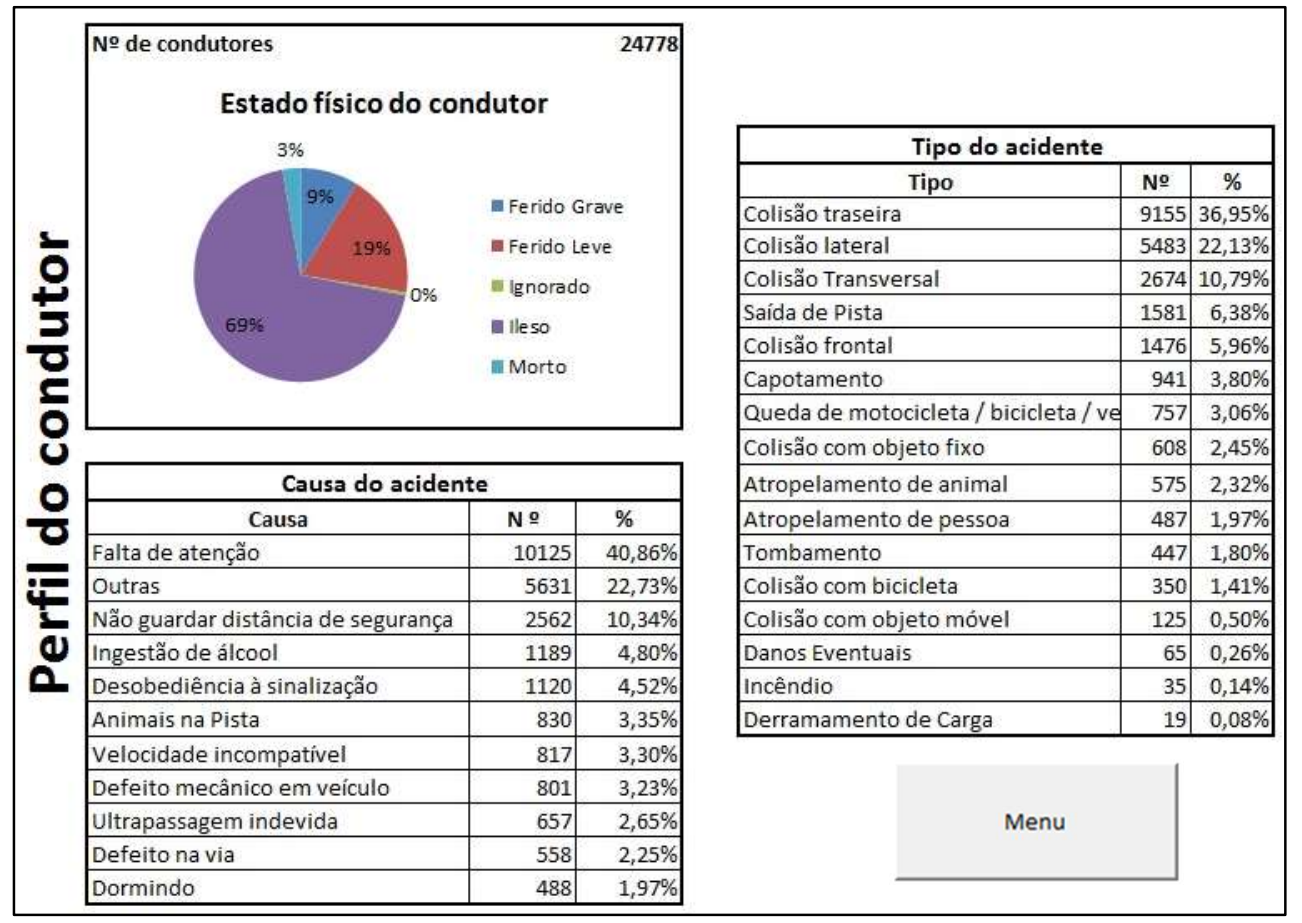

Figura 7 - Dados descritivos do perfil do condutor.

Fonte: os autores (2017).

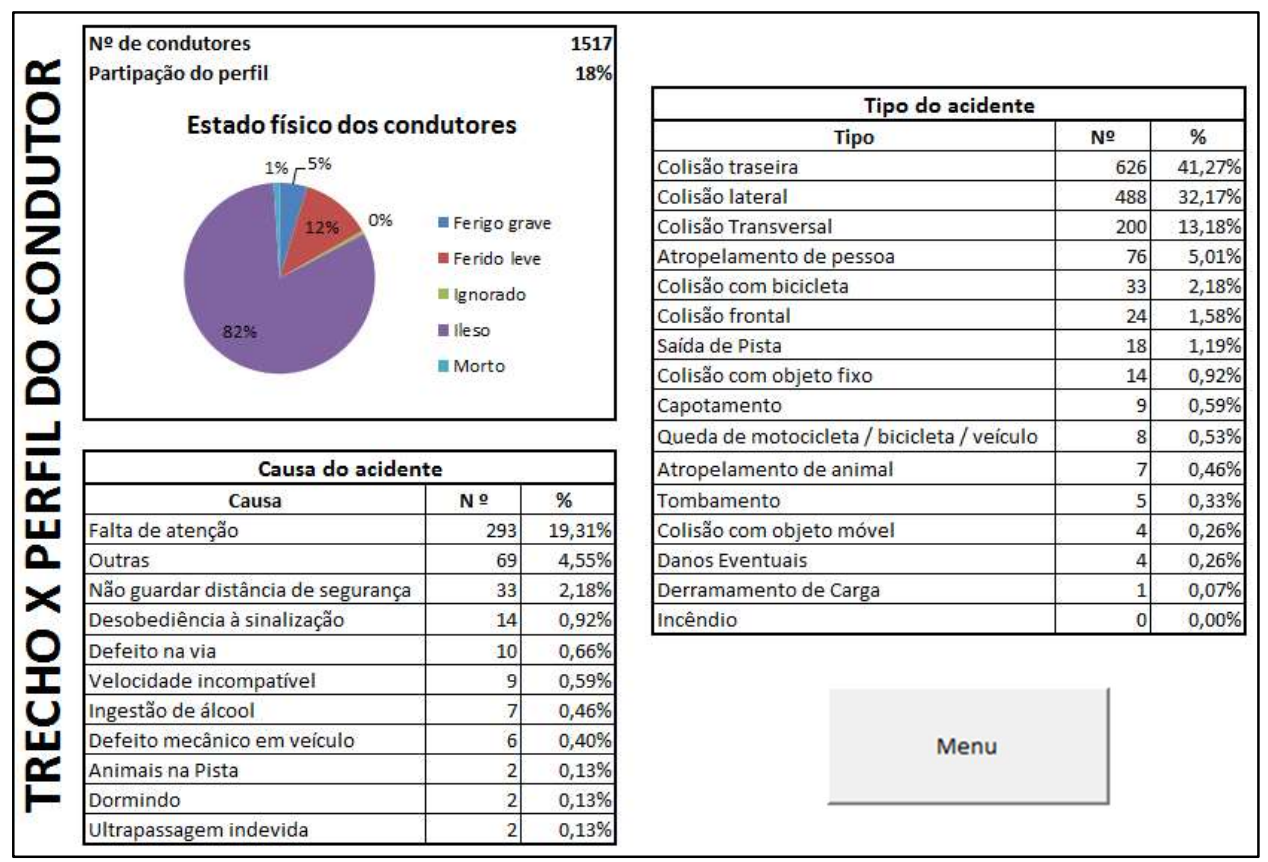

Figura 8 - Dados descritivos do trecho x perfil do condutor.

Fonte: os autores (2017). 
Na Figura 9 tem-se a tela do "Trecho x Veículo" a qual possui os mesmos resultados mencionados anteriormente só que referência à relação do trecho com o veículo escolhido, o mesmo vale para a Figura 10, esta, com os resultados da relação ao trecho com o perfil do condutor e o veículo escolhido mostrados na tela "Trecho x Condutor x Veículo".

\begin{tabular}{|c|c|c|c|c|c|c|c|c|}
\hline \multirow{10}{*}{\multicolumn{2}{|c|}{$\begin{array}{l}\text { № de veículos } \\
\text { Participação } \\
\text { Estado físico do c } \\
91 \%\end{array}$}} & & \multicolumn{4}{|c|}{ Tipo do acidente } \\
\hline & & \multirow{7}{*}{\multicolumn{3}{|c|}{$\begin{array}{l}\text { Indutor } \\
\text { = Ileso } \\
\text { = Ignorado } \\
\text { = Ferido leve } \\
\text { = Ferigo grave } \\
\text { = Morto }\end{array}$}} & \multicolumn{2}{|r|}{ Tipo } & № & $\%$ \\
\hline & & & & & Colisão trasei & & 1755 & $42,84 \%$ \\
\hline & & & & & Colisão latera & & 1532 & $37,39 \%$ \\
\hline & & & & & Colisão Trans & & 494 & $12,06 \%$ \\
\hline & & & & & Atropelamen & e pessoa & 95 & $2,32 \%$ \\
\hline & & & & & Colisão com c & to fixo & 59 & $1,44 \%$ \\
\hline & & & & & Saída de Pista & & 42 & $1,03 \%$ \\
\hline & & & & & Colisão front & & 34 & $0,83 \%$ \\
\hline & & & & & Colisão com b & leta & 28 & $0,68 \%$ \\
\hline \multicolumn{5}{|c|}{ Causa do acidente } & Capotamento & & 24 & $0,59 \%$ \\
\hline & Causa & & $\mathrm{N} \cong$ & $\%$ & Atropelamen & e animal & 18 & $0,44 \%$ \\
\hline & Falta de atenção & & 2420 & $59,07 \%$ & Colisão com c & to móvel & 6 & $0,15 \%$ \\
\hline & Outras & & 691 & $16,87 \%$ & Queda de mo & cleta / bicicleta / veiculo & 4 & $0,10 \%$ \\
\hline & Não guardar distância de segu & nça & 417 & $10,18 \%$ & Danos Eventu & & 3 & $0,07 \%$ \\
\hline & Velocidade incompativel & & 147 & $3,59 \%$ & Incêndio & & 2 & $0,05 \%$ \\
\hline & Ingestão de álcool & & 121 & $2,95 \%$ & Tombamento & & 1 & $0,02 \%$ \\
\hline & Desobediência à sinalização & & 117 & $2,86 \%$ & \multirow{6}{*}{\multicolumn{2}{|c|}{ Menu }} & & \\
\hline & Defeito na via & & 62 & $1,51 \%$ & & & & \\
\hline & Defeito mecânico em veículo & & 41 & $1,00 \%$ & & & & \\
\hline & Ultrapassagem indevida & & 41 & $1,00 \%$ & & & & \\
\hline & Animais na Pista & & 22 & $0,54 \%$ & & & & \\
\hline & Dormindo & & 18 & $0,44 \%$ & & & & \\
\hline
\end{tabular}

Figura 9 - Dados descritivos do trecho x veículo.

Fonte: os autores (2017).

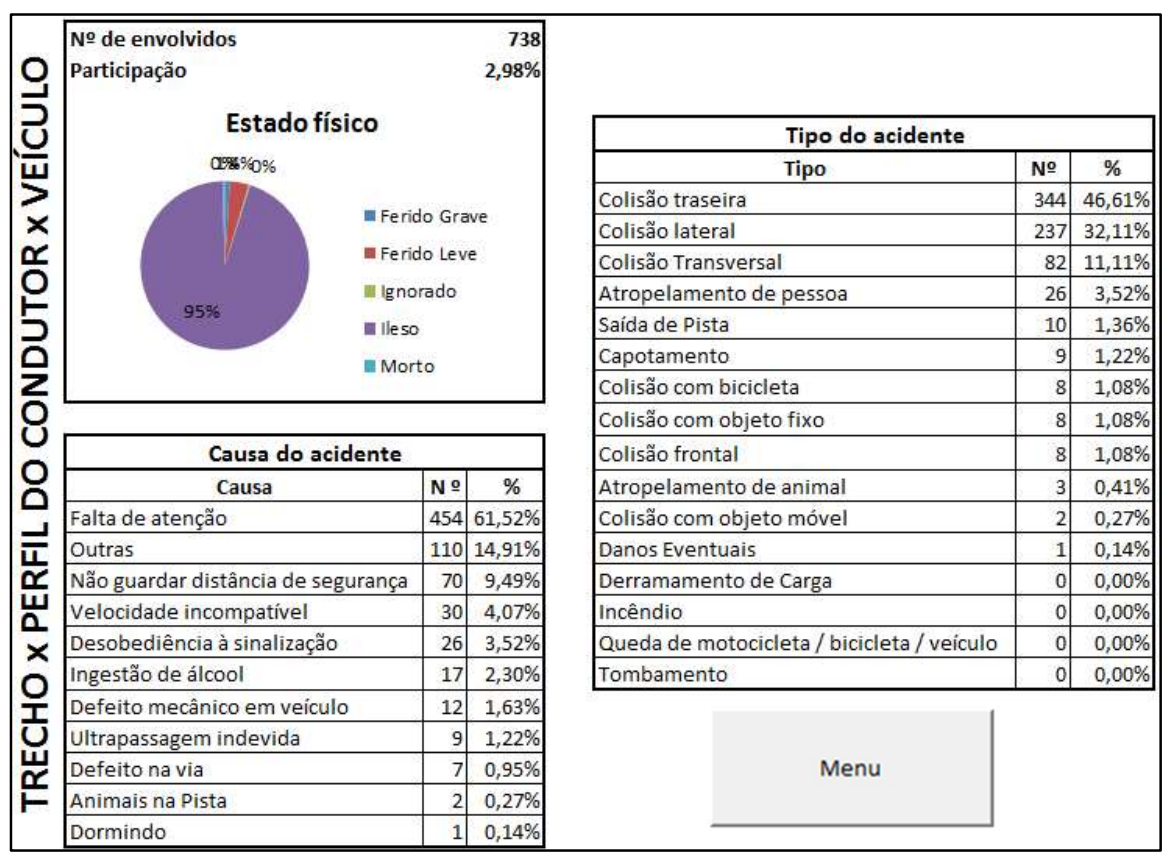

Figura 10 - Dados descritivos do trecho x perfil do condutor x veículo. Fonte: os autores (2017).

Em todas as telas com exceção da tela inicial, há um botão chamado "Menu", ao apertá-lo o usuário será direcionado para o menu principal. 
Partindo das análises exploratórias dos dados, tem-se os resultados gerados na aba “Associações" (Figura 11 e Figura 12). Os resultados das associações do perfil do condutor (sexo/idade) (Figura 11) com as causas, tipos de acidentes e estado físico, na primeira coluna além do perfil do condutor, estão às qualidades do referido ponto dentro da análise de correspondência; na segunda coluna estão listadas as variáveis (causas, estado físico, tipo de acidente); na terceira coluna está a distância euclidiana (proveniente da análise cluster) entre o ponto analisado e o perfil do condutor, essa distância é normalizada para ficar entre 0 e 1 sendo colocada na quarta coluna; na quinta coluna está a ordem da variável que mais está associada aquele perfil inserido pelo usuário (em ordem decrescente); na sétima coluna encontra-se a descrição do grau de associação que o valor normalizado possui; e na última coluna estão as qualidades dos pontos dentro da análise de correspondência - a qualidade dos pontos corresponde a quanto cada ponto está, ou não, bem representado no subespaço definido pelo maior número de dimensões, representando a proporção da contribuição de cada ponto para inércia total.

Vale ressaltar que na coluna da normalização, os valores foram divididos em percentis, com valor mínimo de $25 \%$, médio de $50 \%$ e máximo de $75 \%$, utilizando para isso uma escala tricolor.

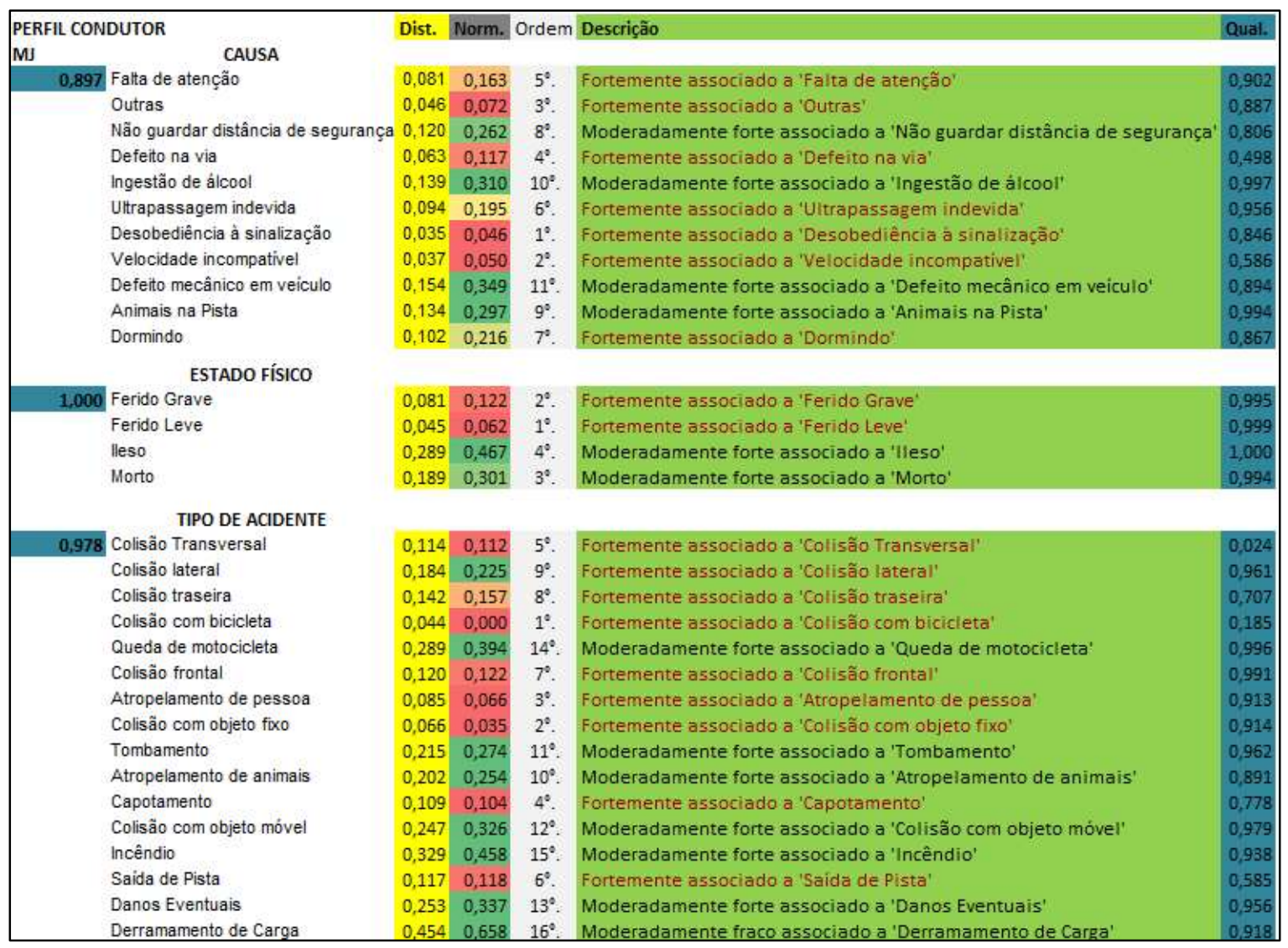

Figura 11 - Resultado das associações (perfil do condutor).

Fonte: os autores (2017).

Como análise dessas informações, no exemplo aplicado, o usuário facilmente percebe que seu perfil de condutor está fortemente associado às causas de "desobediência a sinalização" (1.), "velocidade incompatível" $\left(2^{\circ}\right.$.) e "outras" $\left(3^{\circ}.\right)$, sendo que a causa "velocidade incompatível” possui uma qualidade baixa $(0,586)$. Portanto, deve-se considerar que essa associação não tem uma boa representação pelos dados ocorridos. Além disso, avaliando o perfil do condutor pelo estado físico decorrente do acidente é fortemente associado a ferimentos leves $\left(1^{\circ}\right.$.) e graves $\left(2^{\circ}.\right)$; com os tipos de acidentes fortemente associados com "colisão com bicicleta" ( $1^{\circ}$.), "colisão com objeto fixo" $\left(2^{\circ}\right.$.), "atropelamento de pessoas" $\left(3^{\circ}\right.$.), etc. Da mesma forma, observa-se que a qualidade da representação do tipo "colisão com bicicleta" é muito baixa $(0,185)$, portanto, deve-se ter bastante atenção ao usar essa informação. 


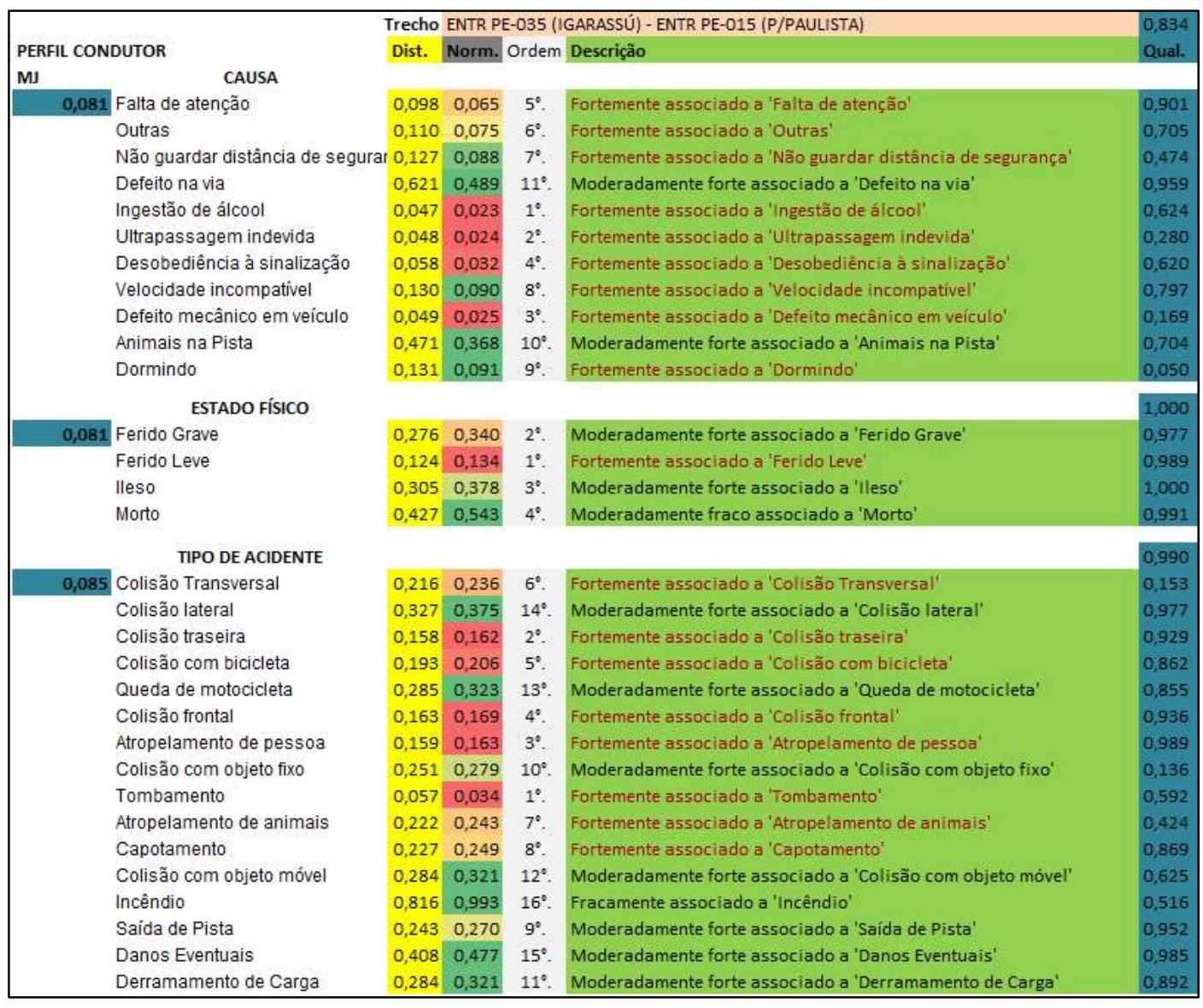

Figura 12 - Resultado das associações (perfil condutor e trecho).

Fonte: os autores (2017).

A Figura 12 mostra as mesmas informações descritas anteriormente, com a diferença que agora diz respeito às associações do perfil do condutor dentro do trecho escolhido. Comparando a Figura 11 com a Figura 12 notase que a ordem final não necessariamente é a mesma para o mesmo perfil dado, mostrando assim que cada trecho pode ter suas particularidades quando comparada ao resultado global. Por exemplo, as três primeiras causas na Figura 11 que são: desobediência à sinalização, velocidade incompatível e outras, dão lugar a ingestão de álcool, ultrapassagem indevida e defeito mecânico em veículo (Figura 12).

De forma análoga a Figura 11 e a Figura 12, são construídas as Figura 13 e Figura 14, com a diferença que em vez de ser analisado o perfil do condutor, agora as informações são geradas de acordo com o tipo de veículo inserido, tanto de uma visão global, quanto filtrado para o trecho.

Por se tratar de um protótipo, o SI encontra-se limitado. Porém, através deste protótipo é possível mostrar sua usabilidade e importância. De forma simplificada, o SI permite conhecer o panorama da acidentalidade de acordo com o perfil indicado.

As informações fornecidas da Figura 6 até a Figura 10 (resultados da estatística descritiva), mostram de maneira simples e de fácil entendimento um panorama geral da acidentalidade dentro dos perfis. Por exemplo, o usuário pode conhecer quais são as causas e tipos de acidentes mais comuns para o trecho. Já da Figura 11 até a Figura 14 é possível inferir, por exemplo, quais as causas estão mais associadas ao veículo o qual o condutor está dirigindo dentro do trecho especificado, permitindo que o usuário tome conhecimento sobre as causas de acidentes mais associadas a ele; para essa tela, é recomendável que o usuário tenha conhecimento básico sobre a análise de correspondência para não interpretar as informações de forma enganosa. 


\begin{tabular}{|c|c|c|c|c|c|c|}
\hline \multicolumn{7}{|c|}{ PERFIL DO VEÍCULO } \\
\hline Automóvel & CAUSA & Dist. & Norm. & Ordem & Descrição & Qual. \\
\hline \multicolumn{2}{|c|}{0,944 Animais na pista } & 0,031 & 0,000 & $1^{\circ}$. & Fortemente associado a 'Animais na pista' & 0,156 \\
\hline \multirow[t]{11}{*}{ 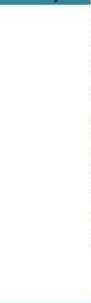 } & Defeito mecânico no veiculo & 0,574 & 0,777 & $11^{\circ}$. & Fracamente associado a 'Defeito mecânico no veículo' & 0,975 \\
\hline & Defeito na via & 0,183 & 0,218 & $6^{\circ}$. & Fortemente associado a 'Defeito na via' & 0,799 \\
\hline & Desobediência à sinalização & 0,365 & 0,478 & $9^{\circ}$. & Moderadamente forte associado a 'Desobediência à sinalização' & 0,947 \\
\hline & Dormindo & 0,374 & 0,491 & $10^{\circ}$. & Moderadamente forte associado a 'Dormindo' & 0,851 \\
\hline & Falta de atenção & 0,079 & 0,068 & $2^{\circ}$. & Fortemente associado a 'Falta de atenção' & 0,010 \\
\hline & Ingestão de âlcool & 0,333 & 0,432 & $8^{\circ}$. & Moderadamente forte associado a 'Ingestão de álcool' & 0,958 \\
\hline & Não guardar distância de segurança & 0,144 & 0,162 & $5^{\circ}$. & Fortemente associado a 'Não guardar distância de segurança' & 0,956 \\
\hline & Outras & 0,125 & 0,135 & $4^{\circ}$. & Fortemente associado a 'Outras' & 0,752 \\
\hline & Ultrapassagem indevida & 0.187 & 0,222 & $7^{\circ}$. & Fortemente associado a 'Ultrapassagem indevida' & 0,762 \\
\hline & Velocidade incompativel & 0,116 & 0,121 & $3^{\circ}$. & Fortemente associado a 'Velocidade incompativel' & 0,724 \\
\hline & \multicolumn{6}{|l|}{ ESTADO FísICO } \\
\hline \multicolumn{2}{|c|}{1,000 Ferido Grave } & 1,549 & 0,843 & $4^{\circ}$. & Fracamente associado a 'Ferido Grave' & 1,000 \\
\hline & Ferido Leve & 1,285 & 0,696 & $2^{\circ}$. & Moderadamente fraco associado a 'Ferido Leve' & 1,000 \\
\hline & Ileso & 0,108 & 0,040 & $1^{\circ}$. & Fortemente associado a 'lleso' & 1,000 \\
\hline & Morto & 1,510 & 0,822 & $3^{\circ}$. & Fracamente associado a 'Morto' & 1,000 \\
\hline \\
\hline \multicolumn{7}{|c|}{$5^{\circ}$. Fortemente associado a 'Atropelamento de animais' } \\
\hline & Capotamento & 0,316 & 0,122 & $4^{\circ}$. & Fortemente associado a 'Capotamento' & 0,915 \\
\hline & Saida de Pista & 0,118 & 0,041 & $3^{\circ}$. & Fortemente associado a 'Saida de Pista' & 0,819 \\
\hline & Colisão com objeto fixo & 0,055 & 0,016 & $2^{\circ}$. & Fortemente associado a 'Colisão com objeto fixo' & 0,775 \\
\hline & Colisão frontal & 0,441 & 0,173 & $7^{\circ}$. & Fortemente associado a 'Colisão frontal' & 0,959 \\
\hline & Colisão traseira & 0,027 & 0,004 & $1^{\circ}$. & Fortemente associado a 'Colisão traseira' & 0,981 \\
\hline & Danos Eventuais & 0,763 & 0,304 & $12^{\circ}$. & Moderadamente forte associado a 'Danos Eventuais' & 0,964 \\
\hline & Colisão Transversal & 0,477 & 0,188 & $8^{\circ}$. & Fortemente associado a 'Colisão Transversal' & 0,978 \\
\hline & Colisão lateral & 0,425 & 0,166 & $6^{\circ}$. & Fortemente associado a 'Colisão lateral' & 0.919 \\
\hline & Colisão com bicicleta & 0,529 & 0,208 & $10^{\circ}$. & Fortemente associado a 'Colisão com bicicleta' & 0,735 \\
\hline & Atropelamento de pessoa & 0,608 & 0,241 & $11^{\circ}$. & Fortemente associado a 'Atropelamento de pessoa' & 0,840 \\
\hline & Tombamento & 1,351 & 0,544 & $14^{\circ}$. & Moderadamente fraco associado a 'Tombamento' & 0,916 \\
\hline & Colisão com objeto móvel & 0,480 & 0,189 & $9^{\circ}$ & Fortemente associado a 'Colisão com objeto móvel' & 0,905 \\
\hline & Incêndio & 0,769 & 0,306 & $13^{\circ}$. & Moderadamente forte associado a 'Incêndio' & 0,798 \\
\hline & Queda de motocicleta & 2,400 & 0,970 & $16^{\circ}$. & Fracamente associado a 'Queda de motocicleta' & 0,995 \\
\hline & Derramamento de Carga & 1,766 & 0,712 & $15^{\circ}$. & Moderadamente fraco associado a 'Derramamento de Carga' & 0,942 \\
\hline
\end{tabular}

Figura 13 - Resultado das associações (veículo).

Fonte: os autores (2017).

\begin{tabular}{|c|c|c|c|c|c|}
\hline \multirow[t]{2}{*}{ Automóvel } & \multicolumn{4}{|c|}{ Trecho ENTR PE-035 (IGARASSÚ) - ENTR PE-015 (P/PAULISTA) } & \multirow[b]{2}{*}{ Qual. } \\
\hline & Dist. & Norm. & Ordem & Descrição & \\
\hline Animais na pista & 2,146 & 0,290 & $11^{\circ}$. & Moderadamente forte associado a 'Animais na pista' & 0,994 \\
\hline Defeito mecânico no veículo & 0,347 & 0,044 & $7^{\circ}$. & Fortemente associado a 'Defeito mecânico no veiculo' & 0,302 \\
\hline Defeito na via & 0,470 & 0,061 & $9^{\circ}$. & Fortemente associado a 'Defeito na via' & 0,648 \\
\hline Desobediência à sinalização & 0,542 & 0,071 & $10^{\circ}$. & Fortemente associado a 'Desobediência à sinalização' & 0,862 \\
\hline Dormindo & 0,171 & 0,020 & $6^{\circ}$. & Fortemente associado a 'Dormindo' & 0,116 \\
\hline Falta de atenção & 0,033 & 0,001 & $1^{\circ}$. & Fortemente associado a 'Faita de atenção' & 0,106 \\
\hline Ingestão de álcool & 0,368 & 0,047 & $8^{\circ}$. & Fortemente associado a 'Ingestão de álcool' & 0,582 \\
\hline Não guardar distância de segurança & 0,141 & 0,016 & $5^{\circ}$. & Fortemente associado a 'Não guardar distância de segurança' & 0,555 \\
\hline Outras & 0,054 & 0,004 & $3^{\circ}$. & Fortemente associado a 'Outras' & 0,059 \\
\hline Ultrapassagem indevida & 0,121 & 0,013 & $4^{\circ}$. & Fortemente associado a 'Ultrapassagem indevida' & 0,079 \\
\hline Velocidade incompativel & 0,054 & 0,004 & $2^{\circ}$. & Fortemente associado a 'Velocidade incompativel' & 0,005 \\
\hline \multicolumn{3}{|l|}{ ESTADO FÍsICO } & & & 0,999 \\
\hline Ferido Grave & 2,462 & 0,828 & $4^{\circ}$. & Fracamente associado a 'Ferido Grave' & 0,980 \\
\hline Ferido Leve & 2,088 & 0,700 & $2^{\circ}$. & Moderadamente fraco associado a 'Ferido Leve' & 0,996 \\
\hline |lleso & 0,055 & 0,006 & $1^{\circ}$. & Fortemente associado a 'lleso' & 1,000 \\
\hline Morto & 2,429 & 0,817 & $3^{\circ}$. & Fracamente associado a 'Morto' & 0,977 \\
\hline \multicolumn{5}{|l|}{ TIPO DE ACIDENTE } & 0,356 \\
\hline Atropelamento de animais & 0,470 & 0,074 & $9^{\circ}$. & Fortemente associado a 'Atropelamento de animais' & 0,094 \\
\hline Capotamento & 0,268 & 0,041 & $7^{\circ}$. & Fortemente associado a 'Capotamento' & 0,010 \\
\hline Saida de Pista & 0,186 & 0,028 & $5^{\circ}$. & Fortemente associado a 'Saida de Pista' & 0,033 \\
\hline Colisão com objeto fixo & 0,062 & 0,008 & $2^{\circ}$. & Fortemente associado a 'Colisão com objeto fixo' & 0,029 \\
\hline Colisão frontal & 0,908 & 0,144 & $12^{\circ}$. & Fortemente associado a 'Colisão frontal' & 0,713 \\
\hline Colisão traseira & 0,055 & 0,007 & $1^{\circ}$. & Fortemente associado a 'Colisão traseira' & 0,206 \\
\hline Danos Eventuais & 0,162 & 0,024 & $4^{\circ}$. & Fortemente associado a 'Danos Eventuais' & 0,076 \\
\hline Colisão Transversal & 0,507 & 0,080 & $10^{\circ}$. & Fortemente associado a 'Colisão Transversal' & 0,871 \\
\hline Colisão lateral & 0,224 & 0,034 & $6^{\circ}$. & Fortemente associado a 'Colisão lateral' & 0,737 \\
\hline Colisão com bicicleta & 4,687 & 0,755 & $16^{\circ}$. & Fracamente associado a 'Colisão com bicicleta' & 1,000 \\
\hline Atropelamento de pessoa & 0,881 & 0,140 & $11^{\circ}$. & Fortemente associado a 'Atropelamento de pessoa' & 0,778 \\
\hline Tombamento & 0,135 & 0,020 & $3^{\circ}$. & Fortemente associado a 'Tombamento' & 0,017 \\
\hline Colisão com objeto móvel & 0,956 & 0,152 & $13^{\circ}$. & Fortemente associado a 'Colisão com objetoto móvel' & 0,030 \\
\hline Incêndio & 0,315 & 0,049 & $8^{\circ}$. & Fortemente associado a 'Incêndio' & 0,056 \\
\hline Queda de motocicleta & 1,635 & 0,262 & $15^{\circ}$. & Moderadamente forte associado a 'Queda de motocicleta' & 0,399 \\
\hline Derramamento de Carga & 1,573 & 0,252 & $14^{\circ}$. & Moderadamente forte associado a 'Derramamento de Carga' & 0,343 \\
\hline
\end{tabular}

Figura 14 - Resultado das associações (veículo e trecho).

Fonte: os autores (2017). 
O SI proposto atende aos usuários tais como condutores em geral, o poder público e privado; para os condutores, o SI proposto pode auxiliar na identificação dos principais tipos de causas e tipos de acidentes, na qual o condutor deve dedicar uma maior atenção, e o quanto aquele trecho por qual ele vai passar está exposto à acidentes e suas respectivas gravidades, permitindo ao decisor em uma posterior decisão a trocar da rota de viagem para uma rota mais "tranquila" caso o usuário (condutor), por exemplo, seja muito avesso ao risco. Já para o poder público, o SI proposto facilita a tomada de decisão, na qual através dele é possível verificar com facilidade as principais características do condutor, do trecho e do tipo de veículo, norteando assim decisões, por exemplo, para priorização em quais trechos agir ou em qual perfil de condutor ele deve atuar para diminuir o risco de acidentes, tais como de melhorias de trechos, manutenção, possíveis programas de prevenção de acidentes, etc.

Portanto, a partir do SI proposto pode-se obter informações sobre a acidentalidade das rodovias federais de Pernambuco de maneira eficiente, pois o resultado será exposto de forma rápida, intuitiva e descomplicada. Desta forma, permitindo ao usuário acesse as informações desejas sem gastar muito tempo dentro do SI.

Além disso, o sistema trabalha com um posterior BD já estruturado, ou seja, o gasto operacional se limita a operações simples de encontrar a informação requisitada dentro do banco existente, não realizando operações que exijam muito do usuário ou do sistema. O sistema pode ser visto como eficaz pois ele cumpre com o proposto, que é mostrar as informações sobre as configurações dos acidentes. Adicionalmente, como as entradas são selecionadas por meio de listas, evita-se erros por parte do usuário e consequentemente evitando inconsistências da saída do sistema. Como principal limitação destaca-se que o SI não se comunica diretamente com o banco de dados da PRF, sendo necessário um pré-processamento (validação) dos mesmos para então disponibilização no SI proposto.

\section{Conclusões}

O presente trabalho cumpriu com o objetivo geral de desenvolver um SI para facilitar o acesso a informações sobre acidentes de trânsito em Pernambuco. A utilização de um sistema como este permite que as informações sejam acessadas de forma rápida quando comparada ao acesso direto do banco de dados da PRF, isso porque com o preenchimento de alguns dados de entrada o resultado é obtido de forma resumida, direta e simples; ao contrário caso o acesso fosse ao banco de dados, onde seria visto apenas os dados brutos e necessitaria de uma manipulação extra pelo usuário para que os dados mostrem alguma informação. Além disso, desconhece-se a existência de um SI de livre acesso que disponibilize informação sobre acidentes de trânsito. Como contribuição para literatura, este trabalho vê uma brecha tanto na literatura brasileira, como no dia a dia, a ausência de estudos que trabalhem a geração e acessibilidade de informação sobre acidentes a partir do banco de dados de acidentes disponibilizados, sendo objetivo deste estudo atuar na geração e disponibilização de informação.

O SI permite que as informações possam ser mais acessíveis dado que exige pouco conhecimento sobre o sistema por parte do usuário, aumentando o acesso a informação da população de forma geral. Além disso, os resultados mostrados são simples e de fácil entendimento, requisitando pouco conhecimento de estatística prévio por parte do usuário; com a exceção da aba de associações, onde é recomendado um conhecimento prévio sobre análise de correspondência para um entendimento correto dos resultados.

Conclui-se então que o SI gerado neste estudo é eficiente e eficaz, de tal forma que disponibiliza a informação requisitada de forma simples, rápida e certa, permitindo que diferentes informações sobre os perfis de condutores, dos trechos, veículos e associações entre elas possam ser buscadas. O SI se mostra útil, pois pode auxiliar na geração de conhecimento sobre o panorama da acidentalidade de Pernambuco, indo além da própria disponibilização da informação, visto que a partir do conhecimento obtido, decisões mais adequadas a situação das rodovias podem ser tomadas por parte dos interessados, diminuindo o risco de acidentes.

\section{Agradecimentos}

Este trabalho foi parcialmente apoiado pela Fundação de Amparo à Ciência e Tecnologia do Estado de Pernambuco (FACEPE) (IBPG-0598-3.08/17), Coordenação de Aperfeiçoamento de Pessoal de Nível Superior (CAPES) e pelo Conselho Nacional de Desenvolvimento Científico e Tecnológico (CNPq) (407541/2018-7).

\section{Referências}

DE ALMEIDA, A. T.; RAMOS, F. DE S. Gestão da informação na competitividade das organizações. 2. ed. Recife: Ed. Universitária da UFPE, 2002. 
DOANE, D. P.; SEWARD, L. E. Estatística aplicada à administração e economia. 4. ed. Porto Alegre: Editora, AMGH, 2014.

GREENACRE, M. J. Correspondence Analysis in Practice. 3. ed. Boca Raton, Florida: CRC PRESS-TAYLOR \& FRANCIS GROUP, 2017.

KORCHAGIN, V.; LJAPIN, S.; RIZAEVA, J.; KONOVALOVA, V.. Subsystem of Road Accident Consequences Elimination. Methodology of Subsystem Efficiency Improvement. Transportation Research Procedia, v. 20, n. September 2016, p. 316-320, 2017.

LIMA, JESSICA NAYARA; GARCEZ, T. V. Análise dos acidentes de trânsito na Br-232 de 2007-2012: trançando perfis. XXXV Encontro Nacional de Engenharia de Produção. Anais...Fortaleza/CE: Associação Brasileira de Engenharia de Produção, 2015

LIMA, JÉSSICA NAYARA; GARCEZ, T. V. Estudo exploratório dos acidentes nas rodovias federais do estado de Pernambuco (2007- 2012). XXXVI Encontro Nacional De Engenharia De Producão. Anais...João Pessoa/PB: Associação Brasileira de Engenharia de Produção, 2016.

MARTINS, M. A.; GARCEZ, T. V. Análise de correspondência e de cluster como estratégia exploratória dos acidentes de trânsito nas rodovias federais de Pernambuco: 10 anos de análise (2007-2016). Anais do XXXVIII Encontro Nacional de Engenharia de Produção (ENEGEP), n. XXXVIII, p. 15, 2018.

MARTINS, M. A.; GARCEZ, T. V. Análise descritiva dos acidentes nas rodovias federais de Pernambuco (20072015). Xxxvii Encontro Nacional De Engenharia De Producao, Anais...Joinville/SC: Associação Brasileira de Engenharia de Produção, 2017

MORAIS NETO, O. L.; SILVA, M.; LIMA, C.; MALTA, D.; SILVA JR., J.. Projeto Vida no Trânsito: avaliação das ações em cinco capitais brasileiras, 2011-2012. Epidemiologia e Serviços de Saúde, v. 22, p. 373-382, 2013.

RYDER, B.; GAHR, B.; EGOLF, P.; DAHLINGER, A.; WORTMANN, F.. Preventing traffic accidents with invehicle decision support systems - The impact of accident hotspot warnings on driver behaviour. Decision Support Systems, v. 99, p. 64-74, 2017.

SILVA, P. H. N. DE V.; LIMA, M. L. C.; MOREIRA, R. S.; SOUZA, W. V.; CABRAL, A. P. S.. Estudo espacial da mortalidade por acidentes de motocicleta em Pernambuco. Revista de Saúde Pública, O aleatório de acidentes em pernambuco, v. 45, n. 2, p. 409-415, 14 abr. 2011.

STAIR, R. M.; REYNOLDS, G. W.; DA SILVA, F. S. C. Princípios de sistemas de informação. 9. ed. São Paulo: Cengage Learning, 2011.

TÖRÖK, Á.; PAUER, G.; BERTA, T. Analysing the Impact of Road Information System on Traffic Safety. Procedia Engineering, v. 187, p. 712-721, 2017.

WHO. Global status report on road safety 2018.. Geneva: World Health Organization (CC BY- NC-SA 3.0 IGO), ago. 2018. 